\title{
EFFECT OF FIBRE INCLINATION ANGLES ON THE SUPERELASTIC BEHAVIOUR OF ANNEALED NiTi FIBRES
}

\author{
${ }^{1,2}$ Aravi MUZAFFAR, ${ }^{1}$ Rajesh PRASAD, ${ }^{1}$ Suresh NEELAKANTAN \\ 1'Indian Institute of Technology Delhi, Hauz Khas, India, rajesh@iitd.ac.in, sureshn@iitd.ac.in \\ ${ }^{2}$ National Institute of Technology Srinagar, Kashmir, India, aravimir@gmail.com
}

https://doi.org/10.37904/metal.2021.4223

\begin{abstract}
Metallic networks are promising candidates for new age porous materials wherein porosity is induced by manoeuvring network architecture. Their properties are thus highly dependent on architectural parameters like fibre segment length, orientation of fibres, porosity etc., apart from being dependent on the nature of material and processing conditions. As such, varied networks having diverse properties can be constructed depending on the choice of architectural or structural parameters and fibre material. Shape memory alloys (SMAs), when used to make the network, can bring about additional properties like superelasticity and shape memory effect in network that can be beneficial for increasing the recoverable strain of SMAs. In the current study, the asreceived cold worked Nitinol wire of $0.125 \mathrm{~mm}$ diameter has been considered. In order to achieve the required SMA properties for manifesting the characteristic behaviour of Nitinol, an annealing treatment is needed. The specimens were subjected to heat treatment at $400^{\circ} \mathrm{C}$ for 5,15 and 30 minutes and evolution of transformation temperatures was measured by differential scanning calorimetry (DSC). Further, the effect of fibre orientationa critical structural parameter of the networks - on the shape memory properties of SMAs in the porous network form has been considered. For this, SMA fibre specimens annealed at $400{ }^{\circ} \mathrm{C}$ for 30 min were inclined at different orientations and loaded in tension till fracture. It was observed that with the increase in inclination angle from the loading axis, the plateau and fracture load decreases, whereas the superelastic strain range increases. The SMA deformation characteristics were then modelled in ANSYS software to determine the effect of inclination angles and further validated.
\end{abstract}

Keywords: Shape memory alloys, metallic fibre networks, fibre inclination angle, superelastic behaviour

\section{INTRODUCTION}

The uniqueness of the porous materials lies in their ability to incorporate pores and related characteristics, apart from retaining the inherent properties of their constituent material. Fibrous based porous materials exhibit heterogeneity and high porosity, which widen their application areas, including light weight structures, sound and energy absorption, heat transfer, catalysis, filtration and bioimplants [1-3]. These materials can be made with metal fibres, which are arranged as per a specific architecture to required shape and sintered to establish bonding at the fibre-fibre contacts, after compaction [3,4]. The properties of these networks are dependent on the architectural parameters including fibre orientation, fibre segment aspect ratio and the fibre material. It is thus interesting to explore the combined effect of a fibre being a smart material like Nitinol (alloy of $\mathrm{Ni}$ and $\mathrm{Ti}$ ) and its deformation behaviour influenced by fibre network architectural parameter, such as fibre orientation.

Smart materials like Shape Memory Alloys (SMAs) exhibit properties like superelasticity (SE) and shape memory effect (SME), in response to load application and temperature variations, respectively [5]. Their characteristic behaviour arises due to the presence of austenite $(A)$ and martensite $(M)$ phases and their reversible transformations [6]. A third phase, R-phase $(R)$ can exist in the material either due to the presence of dislocations (cold-working) or annealing of $\mathrm{Ni}$ rich Nitinol at specific temperature ranges or addition of 
elements like Fe [7]. Thermo-mechanical history, thus, influences the response of SMAs to loading. It also regulates the transformation temperatures $A_{s}, A_{f}, M_{s}, M_{f}, R_{s}$ and $R_{f}$, where $A_{s}$ is the austenite start temperature, $\mathrm{A}_{\mathrm{f}}$ is the austenite finish temperature and so on. Taking into consideration the complex behaviour of SMAs and their specific properties, the present study involves determining: (i) the effect of annealing on Nitinol transformation properties and (ii) the effect of fibre inclination angle on the annealed SMAs deformation behaviour, specifically, their superelastic response.

\section{MATERIALS AND METHODS}

Equiatomic NiTi (Nitinol) in the form of wire in cold-worked state with a diameter of $0.125 \mathrm{~mm}$ was procured from Good Fellow Cambridge Ltd., UK. The long wire in the spool was cut in to required sized fibres for further testing and analysis. These fibres were then annealed at $400{ }^{\circ} \mathrm{C}$ for 5,15 and $30 \mathrm{~min}$ in a muffle furnace. The determination of phase transformation temperature of the annealed samples was carried out using differential scanning calorimetry (DSC) (TA instruments, Q 200) by subjecting them to heating and cooling cycles in the temperature range of $-40{ }^{\circ} \mathrm{C}$ to $120^{\circ} \mathrm{C}\left(150{ }^{\circ} \mathrm{C}\right.$ for 5 min annealing $)$ at a rate of $10^{\circ} \mathrm{C} / \mathrm{min}$. The fibre sample annealed at $400{ }^{\circ} \mathrm{C}$ for 30 min was loaded in tensile mode using Zwick-Roell UTM with $1 \mathrm{kN}$ load cell and a heating chamber (RT to $250^{\circ} \mathrm{C}$ ). The fibre samples used for tensile testing were oriented at different angles of $15^{\circ}, 30^{\circ}$ and $45^{\circ}$ with respect to the loading axis, apart from the vertically inclined (i.e., along the loading axis) one, keeping the gauge length as $25 \mathrm{~mm}$. All the samples were loaded at $65^{\circ} \mathrm{C}\left(T>A_{f}\right)$, till fracture while maintaining a crosshead speed of $0.001 \mathrm{~mm} / \mathrm{s}$. Further, the annealed samples (those of vertically aligned and oriented at different angles) were also pulled in tensile mode till $4 \%$ strain and then unloaded to zero-load condition, to determine the superelastic characteristics. The loading-unloading tests were carried out at different testing temperatures, especially above and below the $A_{\mathrm{f}}$ temperature, to determine their influence on the superelastic behaviour. The superelastic behaviour of the vertically aligned fibre was then modelled in ANSYS v18.1 and validated. Considering this model, the unloading characteristics of inclined fibres have been simulated.

\section{RESULTS AND DISCUSSION}

\subsection{Annealing effect on transformation temperatures}

The as-received Nitinol wire was expected to show the suppression of martensitic transformation due to its cold-worked state [8]. The annealing was thus required to decrease the dislocation density and allow the martensitic transformation. It has been suggested that low temperature (i.e., partial) annealing, after coldworking, shows better strength and superelastic characteristics and hence a temperature of $400{ }^{\circ} \mathrm{C}$ was chosen for annealing the specimen [7]. The DSC curves of the annealed specimens are shown in Figure 1a.

The DSC curves show two peaks, one on the heating and the other on the cooling side, having little hysteresis. The peaks are broad for the specimen annealed for $5 \mathrm{~min}$., while they evolve to become narrower for specimens annealed for 15 and 30 min, respectively. The presence of R-phase is expected due to the low hysteresis in the heating and cooling curves (as seen in Figure 1a) and high dislocation density of the asreceived sample [7]. The change in the annealing time, although does not affect the nature of phases formed, is seen to change their transformation temperatures. The effect of annealing time on transition temperature is shown in Figure $\mathbf{1 b}$. The narrowing of the peaks with the increase in the annealing time is observed, resulting in decrease in the temperature hysteresis. This is because the stored elastic energy decreases with annealing [9]. As the transformation temperatures show only a slight change for $30 \mathrm{~min}$ annealing time from $15 \mathrm{~min}$, the former is selected for further investigation. Table 1 shows the measured transformation temperatures for the three cases. 

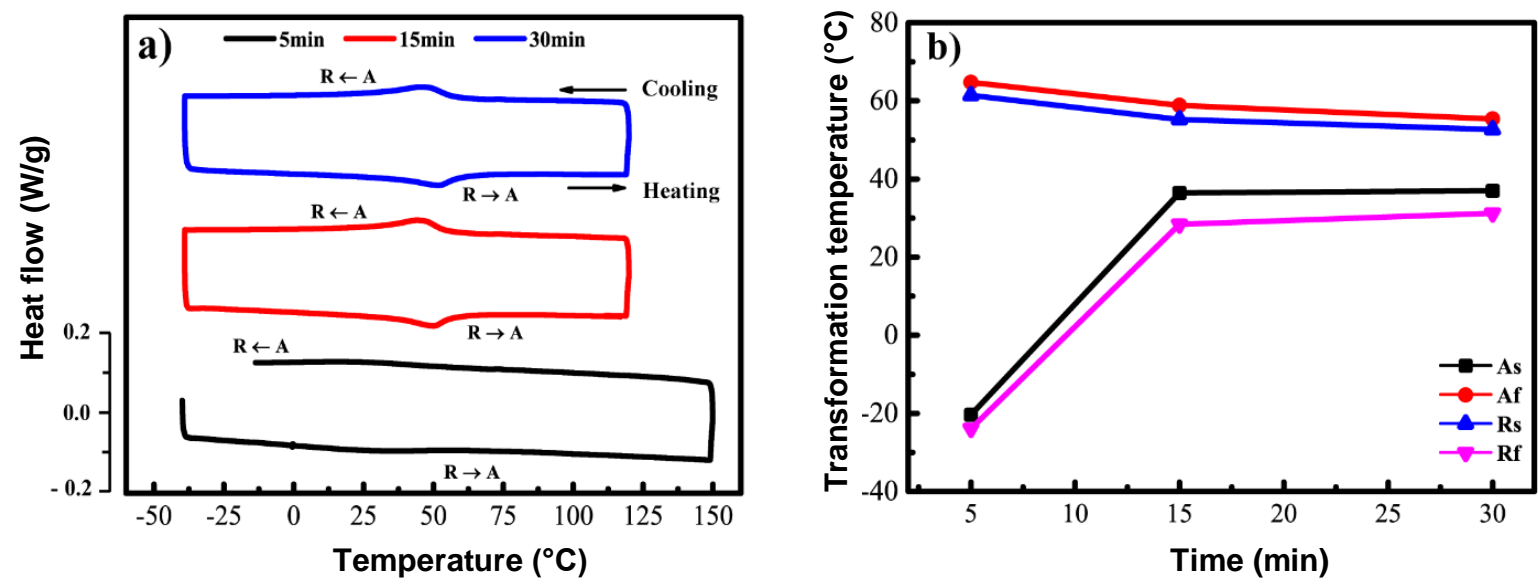

Figure 1 a) DSC curves of Nitinol SMA annealed at $400{ }^{\circ} \mathrm{C}$ for 5,15 and $30 \mathrm{~min}$; b) Effect of annealing time on transformation temperatures of Austenite and R-phase

Table 1 Transition temperatures of equiatomic Nitinol, measured from DSC, after annealing at $400{ }^{\circ} \mathrm{C}$ for different times

\begin{tabular}{|c|c|c|c|c|}
\hline $\begin{array}{c}\text { Annealing time at } \mathbf{4 0 0}{ }^{\circ} \mathrm{C} \\
(\mathrm{min})\end{array}$ & \multicolumn{4}{|c|}{ Transformation temperatures $\left({ }^{\circ} \mathrm{C}\right)$} \\
\cline { 2 - 5 } & $\boldsymbol{A}_{\boldsymbol{s}}$ & $\boldsymbol{A}_{\boldsymbol{f}}$ & $\boldsymbol{R}_{\boldsymbol{s}}$ & $\boldsymbol{R}_{\boldsymbol{f}}$ \\
\hline 5 & -20.37 & 64.71 & 61.38 & -23.91 \\
\hline 15 & 36.43 & 58.86 & 55.23 & 28.42 \\
\hline 30 & 36.97 & 55.41 & 52.64 & 31.21 \\
\hline
\end{tabular}

\subsection{Tensile test till failure}

The vertically aligned and inclined fibres (annealed at $400{ }^{\circ} \mathrm{C}$ for $30 \mathrm{~min}$.) were kept in the heating chamber at $65^{\circ} \mathrm{C}$ and pulled till failure. The results are compared with each other as well as with the as-received sample (aligned along the loading direction) and are shown in Figure 2a. The as-received sample does not show any superelastic plateau due to its cold-worked condition [10,11]. The annealed samples, on the contrary, show Luder band like transformation of austenite to stress induced martensite. Further, the load required for transformation i.e., transformation load, of the annealed samples continuously decreases as the fibre inclination angle is increased. A decrease of about $15 \%$ from vertically aligned fibre to the fibre aligned at $45^{\circ}$ was observed. The plateau range (displacement range for the plateau region), however, shows an increase of about $58 \%$ from the vertically aligned fibre to the $45^{\circ}$ inclined one, as shown in Figure $\mathbf{2 b}$. The increase in the plateau range, corresponding to the Luder band transformation, can be due to longer inclined length of the wire which increases with the angle of inclination. Figure $\mathbf{2} \mathbf{b}$ also represents the decrease in fracture load and increase in the overall displacement with the increase in the inclination of fibre. The fracture load decreased by about $6 \%$, whereas the overall displacement increases from about $16 \%$ to $30 \%$. The increase in the overall displacement required for fracturing the inclined wire at low loads can be the direct manifestation of higher axial and shear force and bending moment for the inclined fibres. Also, if compared to the as-received sample, the fracture load and total displacement of the vertically aligned annealed fibre is observed to be almost $5 \%$ lower and 95\% higher, respectively, thereby showing the influence of annealing on the properties i.e., increase in ductility and decrease in strength.

\subsection{Superelastic behaviour at different temperatures}

The vertically aligned annealed specimen with tensile load - unload cycle was performed at different testing temperatures to determine its superelastic behaviour. The deviation in the behaviour of the inclined fibres from 
the vertically aligned one is a function of the properties of the latter. The superelastic behaviour of the vertically aligned fibre was at temperatures lower and higher than $A_{f}$, as shown in Figure 2c, and compared, to find the optimum temperature for investigating the effect of fibre inclination angle. As shown in Figure $\mathbf{2 d}$, the upper and lower plateau load shows an increasing trend with the increase in the test temperature. At room temperature, the upper plateau load is $6.4 \mathrm{~N}$ which then increases to $8.8 \mathrm{~N}$ (about $37 \%$ increase), when the testing temperature is $65^{\circ} \mathrm{C}$ (above $A_{f}$ ), and the transformation to austenite is complete. This is because the austenite becomes more stable as the test temperature increases and hence requires higher load for initiation of transformation [7]. The lower plateau load also shows a linear trend, showing a $97 \%$ increase with the increase in test temperature. The load hysteresis decreases first and then tends to stabilise as the temperature becomes greater than $A_{f}$.
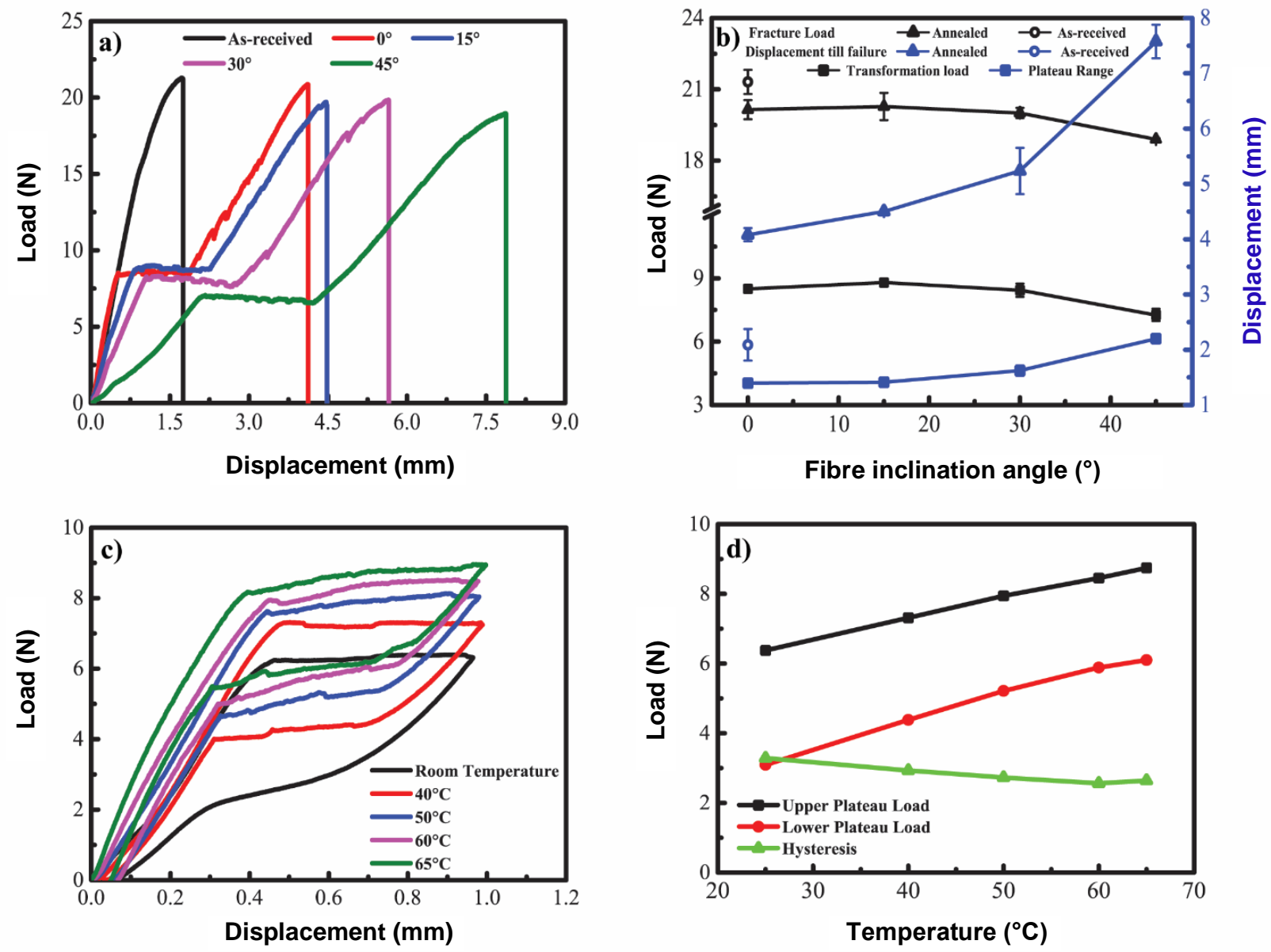

Figure 2 a) Load - displacement curves of as-received and annealed Nitinol fibre samples aligned along the loading axis and $15^{\circ}, 30^{\circ}$ and $45^{\circ}$ away from it; The effect of fibre inclination angle on b) transformation load, plateau range, fracture load and total displacement of the fibre, c) Superelastic curves of Nitinol tested from room temperature to above $A_{f}$ temperatures, and $d$ ) its respective variation of upper and lower plateau load

\subsection{Simulating the superelastic behaviour of inclined fibres}

The loading-unloading characteristics of the annealed sample, oriented along the loading axis (i.e., vertically aligned) and tested at $65^{\circ} \mathrm{C}$, were used in the ANSYS software to simulate the same for the inclined fibres aligned at varied angles with the loading axis. The model in ANSYS v18.1 requires six constants (starting and final stress values for forward and reverse phases, transformation strain and a parameter to measure the difference in the response for tension and compression) to completely simulate the superelastic behaviour of SMAs [12]. The SMA fibre was modelled with diameter as $0.125 \mathrm{~mm}$ and length as $25 \mathrm{~mm}$. One end of the 
fibre was fixed, and displacement was provided to the other end. Optimized FEM parameters with a tetrahedral meshing and an element size of $0.04 \mathrm{~mm}$ was considered for our study. The fibre was pulled to $1 \mathrm{~mm}$ and then unloaded to zero load. The superelastic curve simulated for the vertically aligned fibre was compared with the experimentally obtained curve and a good co-relation was observed as shown in Figure $\mathbf{3 a}$. The validated model was further considered to predict the superelastic behaviour of inclined fibres. Keeping the fibre characteristics same as vertical fibre, the superelastic curves of fibres inclined at $15^{\circ}, 30^{\circ}$ and $45^{\circ}$ inclination angles were predicted, as shown in Figure $\mathbf{3 b}$.
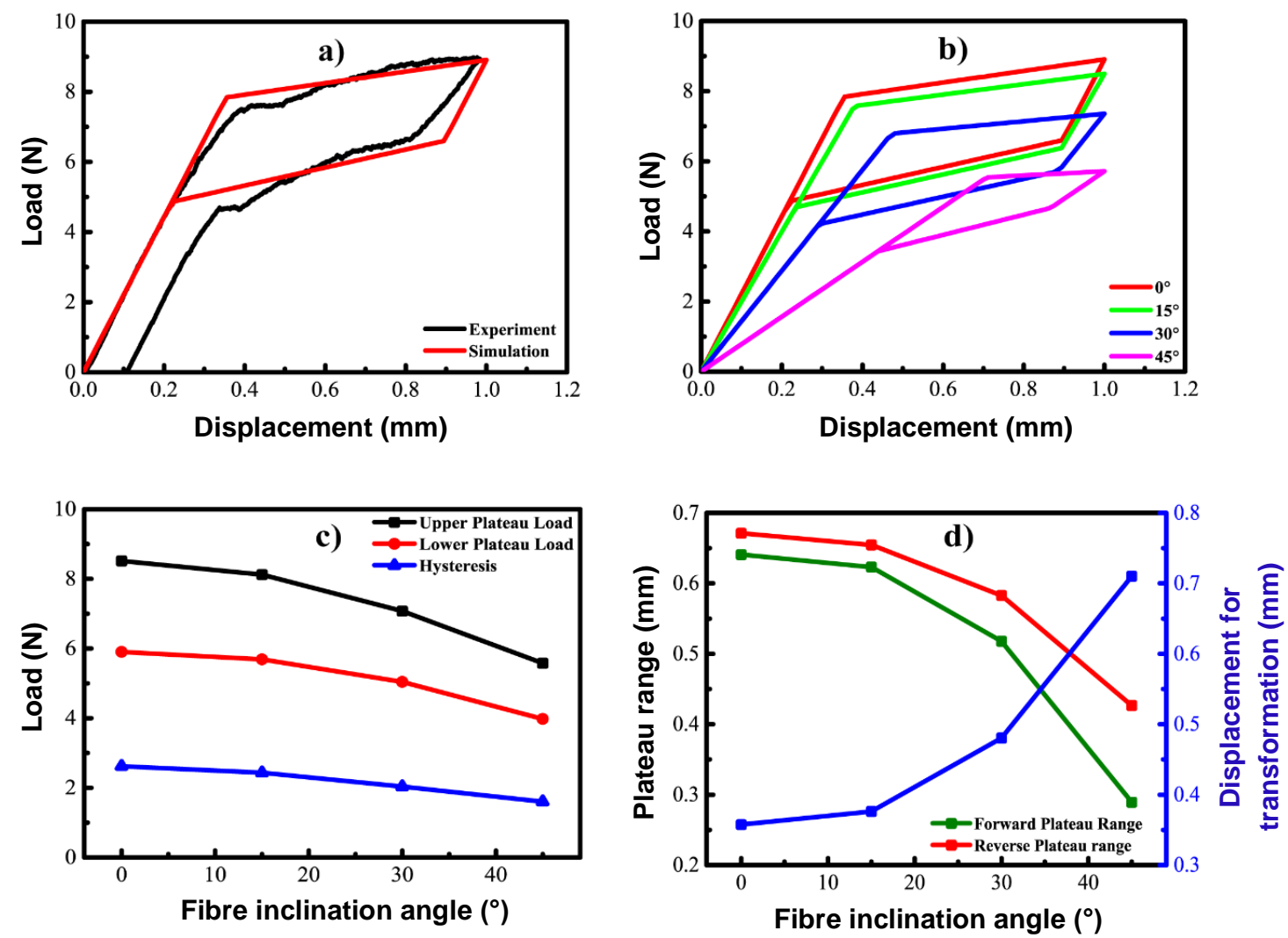

Figure 3 a) Comparison between experimental and simulated (ANSYS) superelastic curves of Nitinol, b) simulated superelastic curves of fibres inclined at $0^{\circ}, 15^{\circ}, 30^{\circ}$ and $45^{\circ}$, the effect of fibre inclination angle on

c) upper and lower plateau load and hysteresis, and d) forward and reverse plateau range and the displacement required for transformation

As the fibre inclination angle increases, the upper and lower plateau load as well as the load hysteresis decreases, as shown in Figure 3c. The upper and lower plateau loads show a decrease of about $35 \%$ and $33 \%$ respectively, while the decrease in hysteresis is seen to be about $39 \%$. The forward and reverse plateau range also decreases when the loaded fibres are extended to $1 \mathrm{~mm}$ and then unloaded, as the transformation of austenite is delayed, and is shown in Figure 3d. The forward plateau range decreases from $0.64 \mathrm{~mm}$ to $0.29 \mathrm{~mm}$ as the fibre inclination angle increases. The reverse plateau range decreases from $0.67 \mathrm{~mm}$ to 0.43 $\mathrm{mm}$ as the displacement required for transformation of austenite increases from $0.36 \mathrm{~mm}$ to $0.71 \mathrm{~mm}$, showing an increase of about $99 \%$. The decrease in plateau load with increasing fibre inclination angle is also observed when they are loaded till failure. This decrease is critical while considering the use of SMA fibres in porous metallic networks. It is to be noted that the increase in the fibre inclination angle may decrease the load required for transformation of austenite and also the fracture load. However, the delay in showing the transformation and increase in the overall displacement may prove beneficial in several structural and bio-medical applications, when combined with their porous nature. 


\section{CONCLUSIONS}

Following conclusions can be drawn from the present study:

i) The Nitinol SMA fibres annealed at $400{ }^{\circ} \mathrm{C}$ exhibits low hysteresis and an increase in transformation temperatures as function of annealing time from $5 \mathrm{~min}$ to $30 \mathrm{~min}$, where the increase is negligible after $15 \mathrm{~min}$.

ii) With the increase in fibre inclination angles from $0^{\circ}$ to $45^{\circ}$ of the annealed SMA fibre, the fracture load decrease by $6 \%$, while the displacement increases by $85 \%$. Further, the transformation load decreases by up to $15 \%$ and the plateau increases to $58 \%$.

iii) The developed and validated ANSYS model for vertically aligned SMA fibre predicts well the superelastic behaviour for inclined fibres. A decrease in upper plateau load of about $35 \%$ and a delay in the start of transformation has been observed with increase in inclination angles.

\section{ACKNOWLEDGEMENTS}

\section{One of the authors acknowledge the support provided by Science and Engineering Research Board (SERB) of DST, India through ECR grant (Ref. no.: ECR/2016/001953).}

\section{REFERENCES}

[1] XI, Z., ZHU, J., TANG, H., AO,Q., ZHI, H., WANG, J., LI, C. Progress of application researches of porous fiber metals. Materials. 2010, vol. 4, pp. 816-824.

[2] LIU, P., HE, G., WU, L.H. Fabrication of sintered steel wire mesh and its compressive properties. Materials Science and Engineering A. 2008, vol. 489, pp. 21-28. ISSN 09215093.

[3] DAVIES, G.J., ZHEN, S. Metallic foams: their production, properties and applications. Journal of Materials Science. 1983, vol. 18, pp. 1899-1911.

[4] ZHOU, W., TANG, Y., PAN, M., WEI, X., XIANG, J. Experimental investigation on uniaxial tensile properties of high-porosity metal fiber sintered sheet. Materials Science and Engineering A. 2009, vol. 525, pp. 133-137.

[5] PETRINI, L., MIGLIAVACCA, F. Biomedical applications of shape memory alloys. Journal of Metallurgy. 2011, vol. 2011, pp. 1-5.

[6] OTSUKA, K., KAKESHITA, T. Science and technology of shape-memory alloys: New developments. MRS Bulletin. 2002, vol. 27, pp. 91-100.

[7] OTSUKA, K., REN, X. Physical metallurgy of Ti-Ni-based shape memory alloys. Progress in Materials Science. 2005, vol. 50, pp. 511-678.

[8] SU, P.C., WU, S. K. The four-step multiple stage transformation in deformed and annealed $\mathrm{Ti}_{49} \mathrm{Ni}_{51}$ shape memory alloy. Acta Materialia. 2004, vol. 52, pp. 1117-1122.

[9] CHROBAK, D., STROZ, D., MORAWIEC, H. Effect of early stages of precipitation and recovery on the multi-step transformation in deformed and annealed near-equiatomic NiTi alloy. Scripta Materialia. 2003, vol. 48, pp. 571576.

[10] MITWALLY, M. E., FARAG, M. Effect of cold work and annealing on the structure and characteristics of NiTi alloy. Materials Science and Engineering A. 2009, vol. 519, pp. 155-166.

[11] ZINELIS, S., ELIADES, T., ELIADES, G. A metallurgical characterization of ten endodontic Ni-Ti instruments: assessing the clinical relevance of shape memory and superelastic properties of $\mathrm{Ni}$ - $\mathrm{Ti}$ endodontic instruments. International Endodontic Journal. 2010, vol. 43, pp. 125-134.

[12] AMIN, S.A., HASSAN, A.Y. Experimental and finite element analyses study of superelasticity behavior of shape memory alloy NiTinol wire. Advances in Natural and Applied Sciences. 2017, vol. 11, pp. 1998-1090. 